\title{
Correlation Between Multielement Stable Isotope Ratio and Geographical Origin in Peretta Cows' Milk Cheese
}

\author{
G. Manca, ${ }^{\star 1}$ M. A. Franco, ${ }^{*}$ G. Versini, $†$ F. Camin $†$ A. Rossmann, $\ddagger$ and A. Tola* \\ *Dipartimento di Chimica, Università di Sassari, 07100 Sassari, Italy \\ †Laboratorio di Analisi e Ricerche, Istituto Agrario di San Michele all'Adige, 38010 S. Michele all'Adige, Trento, Italy \\ †lsolab GmbH Laboratorium für Stabile Isotope, 85301 Schweitenkirchen, Germany
}

\section{ABSTRACT}

The aim of this study was to characterize the isotopic composition and protect "Peretta" cows' milk cheese, a typical product of Sardinia, against other cheeses of the same appearance sold under the same name, but made of raw materials from northern Europe. The study was concerned with 3 types of cheese: those produced in local dairies from milk from free-grazing or pasturegrazing cows in Sardinia (local dairy product), cheeses made on an industrial scale from milk produced by intensive farming in Sardinia (factory cheese), and cheeses made with raw materials imported from other countries (imported product). To distinguish the Sardinian cheeses from the imported product, the stable isotope ratios ${ }^{13} \mathrm{C} /{ }^{12} \mathrm{C},{ }^{15} \mathrm{~N} /{ }^{14} \mathrm{~N}, \mathrm{D} / \mathrm{H},{ }^{34} \mathrm{~S} /{ }^{32} \mathrm{~S}$, and ${ }^{18} \mathrm{O} /$ ${ }^{16} \mathrm{O}$ were used. Determination of the isotopic data $\delta^{13} \mathrm{C}$, $\delta^{15} \mathrm{~N}, \delta^{2} \mathrm{H}$, and $\delta^{34} \mathrm{~S}$ was performed in the casein fraction, whereas $\delta^{18} \mathrm{O}$ and $\delta^{13} \mathrm{C}$ were determined in the glycerol fraction. Measurements were performed by isotope ratio mass spectrometry. A comparison between mean values of the isotope ratios by statistical analysis (ANOVA and Tukey's test) showed that the greatest difference between the 3 types of cheese (local dairy, factory, and imported products) was in the ${ }^{13} \mathrm{C} /{ }^{12} \mathrm{C},{ }^{34} \mathrm{~S} /{ }^{32} \mathrm{~S}$, and ${ }^{18} \mathrm{O} /{ }^{16} \mathrm{O}$ isotope ratios. In the other parameters, either no differences $\left(\delta^{15} \mathrm{~N}\right)$ or minimal differences $\left(\delta^{2} \mathrm{H}\right)$ were found. Evaluation of the data by multivariate statistical analysis (principal component analysis and hierarchical cluster analysis) revealed that the isotope characteristics of the factory products were similar to those of the cheeses produced from imported raw materials, whereas a difference was found between the local dairyproduced cheeses and the products in the other 2 categories.

Key words: Peretta cows' milk cheese, multielement stable isotope ratio analysis, geographic origin

Received February 18, 2005.

Accepted October 18, 2005.

${ }^{1}$ Corresponding author: gmanca@uniss.it

\section{INTRODUCTION}

The growing interest of consumers in regional products whose quality is closely related to a specific geographical area and traditional methods of production means there is a requirement to protect producers of such highly esteemed food from cheaper imitations or counterfeit products. It is therefore necessary to find objective parameters that can correlate these foodstuffs with place of production. Without such information, it is difficult to introduce effective measures to safeguard the products.

One example is "Peretta" cows' milk cheese, a typical product of Sardinia, which has no quality label at present. Cheeses of the same name or with a different name but similar appearance have recently come onto the market. These products have different qualitative characteristics due to the use of raw materials imported from Northern Europe. This may confuse the consumer, who is unable to distinguish them from the original Sardinian products and it may cause commercial disadvantages for the producers of the authentic Peretta cheese. The safeguarding of typical products implies traceability, which is derived from information on the origin of the raw materials, and places and methods of production. The environment is important for both the microbial flora of the milk and the type of pasture, which provides compounds that affect the sensorial qualities of the milk (Beresford et al., 2001; Bugaud et al., 2001; Stefanon and Procida, 2004). Stable isotope techniques in the dairy sector have proved useful in obtaining information on the cows' diet and in identifying the geographic origin of the milk (Camin et al., 2001; Brescia et al., 2003; Renou et al., 2004). The variability of the stable isotope ratio of some bioelements, particularly ${ }^{13} \mathrm{C} /{ }^{12} \mathrm{C},{ }^{15} \mathrm{~N} /{ }^{14} \mathrm{~N}, \mathrm{D} / \mathrm{H}$, and ${ }^{18} \mathrm{O} /{ }^{16} \mathrm{O}$ in some milk and milk product components, reflects variability resulting from the animals' diet (Kornexl et al., 1997; Zainal et al., 1999). By using the isotope ratios ${ }^{13} \mathrm{C} /$ ${ }^{12} \mathrm{C}$ and ${ }^{15} \mathrm{~N} /{ }^{14} \mathrm{~N}$ determined in casein, it is possible to identify diets based on grass or forage in a particular geographical area. The carbon isotope ratio is particularly useful for discovering the presence of any $\mathrm{C}_{4}$ photo- 
synthetic cycle plant supplements, such as corn, which have a higher ${ }^{13} \mathrm{C}$ content than do $\mathrm{C}_{3}$ cycle plants (DeNiro and Epstein, 1978). The nitrogen isotope ratio can provide information about the state of fertilization of pastures (Kreitler and Jones, 1975) and the type of flora present (for instance, clover has a lower ${ }^{15} \mathrm{~N}$ content than other plant species; Yoneyama, 1995). It also indicates the geoclimatic conditions of the area where the cows graze (Mariotti et al., 1981; Amberger and Schmidt, 1987; Heaton, 1987). The isotope characteristics of the water the animals drink from troughs or obtain from a diet rich in fresh forage $\left({ }^{18} \mathrm{O}\right.$-enriched vegetable water; Rossmann et al., 1998) affect the ${ }^{18} \mathrm{O} /$ ${ }^{16} \mathrm{O}$ ratio of the milk and pass into milk and cheese glycerol (Schmidt et al., 2001; Camin et al., 2004). The $\mathrm{D} / \mathrm{H}$ ratio, like the ${ }^{18} \mathrm{O} /{ }^{16} \mathrm{O}$ ratio, is influenced by the characteristics of the water and can indicate the geographic origin of the feed (Clark and Fritz, 1997; Pillonel et al., 2003). The natural abundance of the stable sulfur isotope in plants mostly depends on the distance from the sea and geology of a particular geographical area, and in specific cases, to anthropogenic emissions as well as soil cultivation methods, and can be passed to the animals through their diet, and consequently into their products (Rossmann, 2001). Recent studies have confirmed the validity of stable isotope techniques in identifying the geographic origin of typical cheese (Manca et al., 2001; Brescia et al., 2004). Some studies on cheeses produced in different parts of Italy have shown that the ${ }^{13} \mathrm{C} /{ }^{12} \mathrm{C}$ and ${ }^{15} \mathrm{~N} /{ }^{14} \mathrm{~N}$ ratios determined in the casein and the ${ }^{18} \mathrm{O} /{ }^{16} \mathrm{O}$ in the glycerol fraction are not influenced by season or vintage; however, significant differences exist according to the production area (Chiacchierini et al., 2002; Giaccio et al., 2003). Other studies have reported differences due to seasonal changes in diet (Camin et al., 2004). In view of these results, we decided to conduct a study on the variability of ${ }^{13} \mathrm{C} /{ }^{12} \mathrm{C},{ }^{15} \mathrm{~N} /{ }^{14} \mathrm{~N},{ }^{18} \mathrm{O} /{ }^{16} \mathrm{O}, \mathrm{D} / \mathrm{H}$, and ${ }^{34} \mathrm{~S} /{ }^{32} \mathrm{~S}$ isotope ratios in Peretta cows' milk cheeses to assess the possibility of using these parameters to distinguish Sardinian products from those made from imported raw materials.

\section{MATERIALS AND METHODS}

\section{Sampling}

The object of the study was Peretta, a semicooked, stringy cows' milk cheese obtained by coagulation, mostly by rennet, of heat-treated whole milk at natural acidity or partial fermentation acidity, using liquid or powdered calf rennet. The cheese is pear-shaped (with a head), of uniform elastic texture, straw-colored, and with a thin, smooth rind. The cheese is marketed 1 to $7 \mathrm{~d}$ after production.
Forty-five samples of cheese from local dairies and cheese factories were collected between the end of March and June 2000, the months of highest milk yield. Thirty samples of Peretta were obtained from local dairies ("local dairy products") situated in different parts of Sardinia with different soils and climatic conditions (Barbagia, Gallura, Goceano, Marghine, and Planargia). The milk came from free-grazing or pasture-grazing cows, whose feed was sometimes integrated with fodder and corn flour.

The cheese factories ("factory products") supplied 5 samples of cheeses made from milk produced by intensive farming in which cattle are barn-fed with corn silage and fodder. Other cheese factories in Sardinia provided 10 cheeses ("imported products") made from raw material imported from Northern Europe. All these products look like the cheeses made in local dairies and are marketed in some cases under the name Peretta and sometimes under a different name.

\section{Preparation of Samples to Determine Isotope Ratios}

The ${ }^{13} \mathrm{C} /{ }^{12} \mathrm{C}$ and ${ }^{15} \mathrm{~N} /{ }^{14} \mathrm{~N}$ ratios were measured in the casein fraction of all cheeses whereas D/H and ${ }^{34} \mathrm{~S} /{ }^{32} \mathrm{~S}$ were only determined in 7 local dairy, 4 factory, and 10 imported products. Furthermore, ${ }^{13} \mathrm{C} /{ }^{12} \mathrm{C}$ and ${ }^{18} \mathrm{O} /$ ${ }^{16} \mathrm{O}$ ratios of glycerol were assessed in all samples. The method of extracting the casein and glycerol fractions from the cheeses was described in a previous study (Camin et al., 2004).

The determination of the ratios ${ }^{13} \mathrm{C} /{ }^{12} \mathrm{C}$ (vs. ViennaPee Dee Belemnite) and ${ }^{15} \mathrm{~N} /{ }^{14} \mathrm{~N}$ (vs. air) of the casein and ${ }^{13} \mathrm{C} /{ }^{12} \mathrm{C}$ (vs. Vienna-Pee Dee Belemnite) of the glycerol was performed by isotope ratio mass spectrometry (IRMS; SIRA II-VG Fisons, Rodano, Milan, Italy) coupled with an elemental analyzer (Nitrogen Analyzer 1500, Carlo Erba Strumentazione, Rodano, Milan, Italy), according to the method described in a previous work (Manca et al., 2001).

The glycerol ${ }^{18} \mathrm{O} /{ }^{16} \mathrm{O}$ ratio (vs. Vienna-Standard Mean Ocean Water) was measured by IRMS (Thermo Finnigan Delta-Plus XP, Thermo Finnigan, Bremen, Germany) after pyrolysis of the sample at $1,370^{\circ} \mathrm{C}$ in a dedicated reactor (thermal conversion/elemental analyzer, TC/EA) equipped with an external ceramic tube and internal tube filled with glassy carbon. To avoid moisture adsorption by the highly hygroscopic glycerol during the stages of analysis, samples were weighed (about $1.5 \mathrm{mg}$ ) in silver capsules, placed on the autosampler plate, and put in a desiccator under vacuum and $\mathrm{P}_{2} \mathrm{O}_{5}$ overnight. Immediately before beginning analysis, the plate was put back in the equipment and protected from the air by a covering device under constant nitrogen fluxing. Possible residual adsorption of water was 
checked every 10 analyses, using a glycerol standard to discover any changes in the value. Samples were analyzed in duplicate and values accepted when their difference was lower than $0.6 \%$ (= repeatability limit calculated as $2 \times \operatorname{rad} 2 \times \mathrm{SD}$, where 2 is approximately the Student's $t$ for $P=0.05$ and $\mathrm{v}>10$ and SD is the standard deviation obtained measuring more than 10 times the same glycerol in repeatability conditions). The long-term standard deviation obtained from 10 measurements of the glycerol in-house standard in different runs was $0.4 \%$. Values are referenced against a sucrose in-house standard previously calibrated against the International Atomic Energy Agency (IAEA) reference material cellulose (IAEA-CH3) with a value of $+30.4 \%$, as suggested in the framework of the European Project SMT4-CT98-2219.

For ${ }^{34} \mathrm{~S} /{ }^{32} \mathrm{~S}$ (vs. Vienna-Canyon Diablo Troilite) measurement in casein, an Elementar Vario EL elemental analyzer (Elementar Analysesysteme $\mathrm{GmbH}$, Anan, Germany) coupled with an Analytical Precision (AP 2003,) IRMS (Analytical Precios, now GVI Instruments Ltd., Manchester, UK) was used according to Sieper and Kupka (2003). This system enables the determination of carbon, nitrogen, and sulfur isotopic ratios in one run. Four replicates of a sample (about $3.5 \mathrm{mg}$ each) were weighed into tin capsules and analyzed, obtaining a mean SD of $\pm 0.3 \%$. The reference material was a casein standard (proposed in the European Project SMT4CT98-2236), with a value of 4.4\%o, previously calibrated against Vienna-Canyon Diablo Troilite. The D/H ratio (vs. Vienna-Standard Mean Ocean Water) of casein was measured using a Thermo Finnigan delta XP plus coupled with the high temperature (TC) pyrolysis converter performing pyrolysis at $1,450^{\circ} \mathrm{C}$ according to the method as described by Pillonel et al. (2003). Samples were analyzed in triplicate (sample weighing 0.15 to $0.25 \mathrm{mg}$ ) obtaining a mean SD of $\pm 2 \%$. The calibration and correction of the isotopic ratios for the exchangeable hydrogen of the casein was made applying a similar procedure as suggested by Wassenaar and Hobson (2003). The reference material was the casein standard (see above) with an assigned value of $-113 \%$.

Isotope ratios were expressed as isotope deviation $(\delta$, $\%$ ), defined as $\delta=\left[\left(\mathrm{R}_{\mathrm{s}}-\mathrm{R}_{\mathrm{ref}}\right) / \mathrm{R}_{\mathrm{ref}}\right] \times 1,000$, where $\mathrm{R}_{\mathrm{s}}$ is the isotope ratio measured for the sample and $R_{\text {ref }}$ is the isotope ratio of the reference.

\section{Statistical Analyses}

The minimum, maximum, average, and standard deviations were calculated for each parameter. One-way ANOVA was used to compare mean values. When a significant $F$-value was found, means were separated using Tukey's Honestly Significant Difference test at a confidence level of $95 \%$. Data were analyzed by multivariate statistical analysis; that is, principal component analysis (PCA) and hierarchical cluster analysis (HCA). Principal component analysis is an unsupervised method of pattern recognition that shows the relationship between the samples (objects) on the basis of their distribution in the multidimensional space described from all the variables and also makes it possible to determine which variables are principally responsible for the separation of the objects. Principal component analysis produces linear combinations of original variables that represent, in decreasing order, the directions of the maximum variance in the experimental space under consideration. The main objective is to identify a reduced number of principal components that sufficiently explain most of the information in the starting data. Cluster analysis is a multivariate procedure to detect groupings in the data described by a certain number of variables using the concept of similarity. In the HCA method, clustering begins by finding the closest pair of objects (cases or variables) according to a distance measurement and combines them to form a cluster. The algorithm continues one step at a time, joining pairs of objects, pairs of clusters, or an object with a cluster, until all data are in one cluster. The method is hierarchical because once 2 objects or clusters are joined they remain together until the final step. The stages of clustering are displayed in a graph called a dendrogram. The cluster analysis was done by unweighted pair-group average linkage (between groups) using the square Euclidean distance. All statistical analyses were performed with the software package SPSS 8.0 (SPSS Inc., Chicago, IL).

\section{RESULTS AND DISCUSSION}

Mean, minimum, and maximum values and the standard deviation of the isotope ratios of carbon, nitrogen, and oxygen were determined in casein and glycerol fractions extracted from the cheeses and are shown in Tables 1 and 2 .

The results of the ANOVA (Table 1) show that no significant differences were found according to place of production in the mean values of the carbon, nitrogen, and oxygen isotope ratios in the cheeses produced in local dairies in different parts of Sardinia. The values of $\delta^{13} \mathrm{C}$, determined in the casein fraction, were between -26.72 and $-24.33 \%$ in most of the samples from local dairies, which can be attributed to a diet of grass and forage. The highest values, ranging from -23.48 to $-22.57 \%$, were found in 6 samples ( 1 from Barbagia, 2 from Gallura, 2 from Goceano, and 1 from Marghine) and were probably the result of a larger amount of $\mathrm{C}_{4}$ plants in the diet (Kornexl et al., 1997; Rossmann et 
Table 1. Local dairy-produced cheeses made in Sardinia: basic statistics and results of ANOVA for isotope ratios of carbon, nitrogen, and oxygen $^{1}$

\begin{tabular}{|c|c|c|c|c|}
\hline \multirow[b]{2}{*}{$\begin{array}{l}\text { Region of } \\
\text { Sardinia }\end{array}$} & \multicolumn{4}{|c|}{ Isotope ratio, $\%$} \\
\hline & $\begin{array}{l}\delta^{13} \mathrm{C} \\
\text { (casein) }\end{array}$ & $\begin{array}{l}\delta^{13} \mathrm{C} \\
\text { (glycerol) }\end{array}$ & $\begin{array}{l}\delta^{15} \mathrm{~N} \\
\text { (casein) }\end{array}$ & $\begin{array}{l}\delta^{18} \mathrm{O} \\
\text { (glycerol) }\end{array}$ \\
\hline \multicolumn{5}{|c|}{ Barbagia $(\mathrm{n}=6)$} \\
\hline Mean & $-25.25^{\mathrm{NS}}$ & $-31.25^{\mathrm{NS}}$ & $5.24^{\mathrm{NS}}$ & $21.82^{\mathrm{NS}}$ \\
\hline $\mathrm{SD}$ & 1.22 & 1.49 & 0.70 & 1.69 \\
\hline Minimum & -26.72 & -32.62 & 4.62 & 19.04 \\
\hline Maximum & -23.12 & -28.42 & 6.48 & 23.59 \\
\hline \multicolumn{5}{|c|}{ Gallura $(\mathrm{n}=4)$} \\
\hline Mean & $-24.10^{\mathrm{NS}}$ & $-30.02^{\mathrm{NS}}$ & $5.77^{\mathrm{NS}}$ & $22.14^{\mathrm{NS}}$ \\
\hline SD & 0.81 & 1.24 & 0.54 & 3.75 \\
\hline Minimum & -25.11 & -31.10 & 4.98 & 19.38 \\
\hline \multirow{2}{*}{\multicolumn{5}{|c|}{ Goceano $(\mathrm{n}=9)$}} \\
\hline & & & & \\
\hline Mean & $-25.13^{\mathrm{NS}}$ & $-31.56^{\mathrm{NS}}$ & $5.17^{\mathrm{NS}}$ & $23.27^{\mathrm{NS}}$ \\
\hline SD & 1.27 & 1.78 & 1.11 & 1.20 \\
\hline Minimum & -26.48 & -33.39 & 3.20 & 21.33 \\
\hline Maximum & -22.93 & -27.98 & 7.02 & 25.04 \\
\hline \multicolumn{5}{|c|}{ Marghine $(\mathrm{n}=7)$} \\
\hline Mean & $-25.08^{\mathrm{NS}}$ & $-30.89^{\mathrm{NS}}$ & $5.54^{\mathrm{NS}}$ & $23.55^{\mathrm{NS}}$ \\
\hline SD & 1.35 & 1.57 & 0.63 & 1.28 \\
\hline Minimum & -26.45 & -32.39 & 4.61 & 22.37 \\
\hline Maximum & -22.57 & -28.05 & 6.66 & 26.20 \\
\hline \multicolumn{5}{|c|}{ Planargia $(\mathrm{n}=4)$} \\
\hline Mean & $-25.32^{\mathrm{NS}}$ & $-31.38^{\mathrm{NS}}$ & $6.32^{\mathrm{NS}}$ & $21.85^{\mathrm{NS}}$ \\
\hline SD & 0.54 & 0.58 & 0.91 & 2.67 \\
\hline Minimu & -25.77 & -31.92 & 5.79 & 18.04 \\
\hline Maximum & -24.56 & -30.64 & 7.68 & 24.25 \\
\hline
\end{tabular}

${ }^{1}$ The differences for each isotopic variable among different production areas are not significant.

$\mathrm{NS}=$ No significant difference between mean values $(P>0.05)$ in each column (by ANOVA).

al., 1998). Tukey's test showed significant differences in this parameter between the mean values of the local dairy-produced cheeses, the factory products, and the imported products (Table 2). The last 2 categories had $\delta^{13} \mathrm{C}$ values similar to those found in cows' milk cheeses produced in Northern Italy using milk from intensive farming, in which the cattle are fed supplements or corn silage $\left(\mathrm{C}_{4}\right.$ cycle plants; Camin et al., 2001, 2004). The mean values of $\delta^{13} \mathrm{C}$ found in the glycerol fraction of the cheeses were lower by about 5 to 6 units per thousand (\%o) compared with the values found in casein (Weber et al., 1997). Linear regression analysis of the carbon isotope ratios in the 2 fractions extracted from the cheeses revealed a high correlation between these 2 parameters $(\mathrm{r}=0.962)$. These results confirm reports by other authors (Pillonel et al., 2003) and indicate that the $\delta^{13} \mathrm{C}$ values of both fractions provide information about the cows' diet.

As regards the nitrogen isotope ratio, the differences between the $\delta^{15} \mathrm{~N}$ mean values of the local dairy, factory, and imported products were not significant. Analysis of the data sets of the local dairy products generally showed high variability of this parameter, also within
Table 2. Basic statistics of isotope ratio values of carbon, nitrogen and oxygen in the three types of cheese analyzed and the results of Tukey's Honestly Significant Difference test

\begin{tabular}{lcclc}
\hline & \multicolumn{4}{c}{ Isotope ratio, \%o } \\
\cline { 2 - 5 } & $\delta^{13} \mathrm{C}$ & $\delta^{13} \mathrm{C}$ & $\delta^{15} \mathrm{~N}$ & $\delta^{18} \mathrm{O}$ \\
Cheese type & (casein) & glycerol) & (casein) & (glycerol) \\
\hline Local dairy product $(\mathrm{n}=30)$ & & & \\
$\quad$ Mean & $-25.03^{\mathrm{a}}$ & $-31.11^{\mathrm{a}}$ & $5.51^{\mathrm{a}}$ & $22.70^{\mathrm{a}}$ \\
SD & 1.15 & 1.49 & 0.88 & 2.00 \\
Minimum & -26.72 & -33.39 & 3.20 & 18.04 \\
Maximum & -22.57 & -27.98 & 7.68 & 27.60 \\
Factory product $(\mathrm{n}=5)$ & & & & \\
Mean & $-20.75^{\mathrm{b}}$ & $-25.40^{\mathrm{b}}$ & $5.00^{\mathrm{a}}$ & $20.66^{\mathrm{b}}$ \\
SD & 1.13 & 1.56 & 0.31 & 1.82 \\
Minimum & -22.27 & -27.40 & 4.57 & 17.97 \\
Maximum & -19.52 & -23.73 & 5.30 & 22.49 \\
Imported product $(\mathrm{n}=9)$ & & & & \\
$\quad$ Mean & $-22.24^{\mathrm{c}}$ & $-27.15^{\mathrm{c}}$ & $5.25^{\mathrm{a}}$ & $18.10^{\mathrm{c}}$ \\
SD & 1.59 & 2.18 & 0.18 & 1.00 \\
Minimum & -24.63 & -30.52 & 4.91 & 16.81 \\
Maximum & -19.37 & -23.14 & 5.47 & 19.92 \\
\hline
\end{tabular}

${ }^{a-c}$ Mean values within columns with a different letter are significantly different $(P=0.05)$.

the same area of Sardinia. This could be due to a difference in the state of fertilization of the soil. The most marked differences were found in the Goceano samples, whose $\delta^{15} \mathrm{~N}$ values ranged between 3.20 and 7.02\%o, but as can be seen from the standard deviation values, variability was also high between the samples from the other areas. Furthermore, comparison with previous studies (Camin et al., 2001) shows differences between years of production. If we compare the mean value of $\delta^{15} \mathrm{~N}$ in the samples we analyzed (5.48\%o) with that obtained from an analysis of the cheese collected the previous year $(6.55 \%$ ), differences are observed that seem to reflect variations in the island's aridity over the $2 \mathrm{yr}$.

High variability of $\delta^{18} \mathrm{O}$ was also observed between the local dairy products. No significant differences were found between mean values of samples from different areas, although samples from Goceano and Marghine (inland areas of low hills) tended to have slightly higher values than the others. Apart from 5 samples (2 from Barbagia, 2 from Gallura, and 1 from Planargia), which had the lowest $\delta^{18} \mathrm{O}$ values (varying between 20.74 and $18.04 \%$ o), the samples had values in the range from 27.60 to $21.33 \%$, distinctly higher than the values found in cows' milk cheeses from Northern Europe (Camin et al., 2004). The lowest $\delta^{18} \mathrm{O}$ values may be due to feed that is rich in dry forage. Tukey's test showed significant differences between the mean values of $\delta^{18} \mathrm{O}$ in the 3 categories of products tested (local dairy, factory, and imported).

To identify any similarities and correlations between the 3 types of cheeses, the data set (data set A) of 3 variables $\left(\delta^{13} \mathrm{C}_{\text {(glycerol) }}, \delta^{15} \mathrm{~N}_{\text {(casein) }}\right.$, and $\left.\delta^{18} \mathrm{O}_{\text {(glycerol) }}\right)$ and 


\section{TYPES OF CHEESE}

\section{* Imported product}

- Factory product

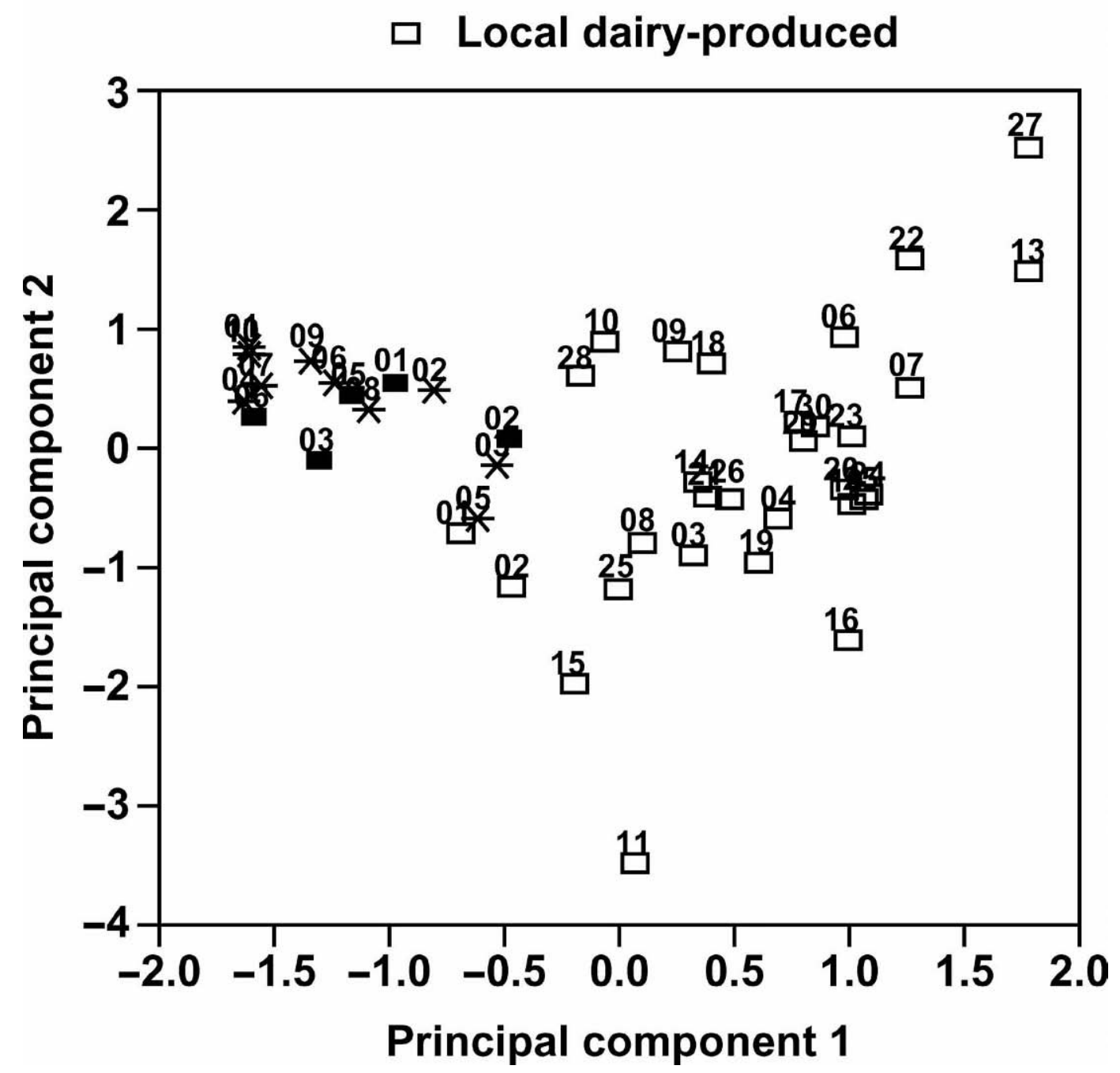

Figure 1. Scatter plot of the scores on the first 2 principal components obtained with data set A of 3 variables and 45 objects. Imported and factory products form a single group, whereas local products are contained in a different group.

45 objects was evaluated by PCA. The individual plane of the first 2 components, accounting for $81 \%$ of total variance, showed that the factory products had similar isotope characteristics to the imported samples. Together, cheeses from these 2 groups formed a single group, together with one local dairy product; all other locally produced cheeses formed a second group (Figure 1).

The first component is positively correlated with the oxygen isotope ratio and negatively correlated with the carbon isotope ratio, whereas the second component is positively correlated with the nitrogen isotope ratio and accounts for $30 \%$ of the variance (Table 3 ).

Hierarchical cluster analysis was used to validate the presence of groups on the same data set (data set A). The dendrogram (Figure 2) shows that the factory and imported samples form a single group, which also contains 5 locally produced samples. The latter have lower $\delta^{18} \mathrm{O}$ values than the other samples in the local product category, which form a second group. 
Table 3. Correlation coefficient between the first 2 principal components and variables and explained variance from each component ${ }^{1}$

\begin{tabular}{lcc}
\hline Variables & $\begin{array}{l}\text { First } \\
\text { component }\end{array}$ & $\begin{array}{l}\text { Second } \\
\text { component }\end{array}$ \\
\hline$\delta^{18} \mathrm{O} \%$ o(glycerol) & 0.827 & -0.133 \\
$\delta^{13} \mathrm{C} \%$ (glycerol) & -0.769 & 0.412 \\
$\delta^{15} \mathrm{~N} \%$ o(casein) & 0.501 & 0.852 \\
Explained variance & & \\
Variance, \% & 50.85 & 30.47 \\
Cumulative variance, \% & 50.85 & 81.32 \\
\hline
\end{tabular}

${ }^{1}$ The first component is correlated with the oxygen and carbon isotope ratios, whereas the second component is correlated with the nitrogen isotope ratio.

Considering that the isotope ratios of carbon, nitrogen, and oxygen do not make an optimal distinction between the categories of products, we decided to test the ability of 2 other isotope ratios, $\mathrm{D} / \mathrm{H}$ and ${ }^{34} \mathrm{~S} /{ }^{32} \mathrm{~S}$, to distinguish between the types of cheeses. Tests were carried out on a group of samples from local dairies, selected to have samples representative of the different areas of Sardinia, and on 4 factory and all imported samples (Table 4). Tukey's Honestly Significantly Different test revealed significant differences between mean values of the sulfur isotope ratio of the 3 types of products. Differences were less marked in $\mathrm{D} / \mathrm{H}$ values, although the local dairy samples tended to have higher values than the imported products.

Because the greatest differences between the 3 categories of products were in the isotope ratios of carbon, oxygen, and sulfur, we proceeded to determine, by mul-
Table 4. Hydrogen and sulfur isotope ratios: basic statistics and results of Tukey's Honestly Significant Difference test

\begin{tabular}{lcc}
\hline & \multicolumn{2}{c}{ Isotope ratio, \%o } \\
\cline { 2 - 3 } & $\begin{array}{l}\delta^{2} \mathrm{H} \\
\text { (casein) }\end{array}$ & $\begin{array}{l}\delta^{34} \mathrm{~S} \\
\text { (casein) }\end{array}$ \\
\hline Local dairy product $(\mathrm{n}=7)$ & & \\
Mean & $-114.98^{\mathrm{a}}$ & $9.32^{\mathrm{a}}$ \\
SD & 4.63 & 1.02 \\
Minimum & -122.98 & 7.11 \\
Maximum & -107.26 & 10.22 \\
Factory product $(\mathrm{n}=4)$ & $-117.61^{\mathrm{a}}$ & \\
Mean & 4.26 & $6.29^{\mathrm{b}}$ \\
SD & -122.98 & 0.83 \\
Minimum & -113.01 & 5.30 \\
Maximum & & 7.19 \\
Imported product $(\mathrm{n}=10)$ & $-130.15^{\mathrm{b}}$ & $4.73^{\mathrm{c}}$ \\
Mean & 8.44 & 0.66 \\
SD & -150.30 & 3.48 \\
Minimum & -121.32 & 6.15 \\
Maximum & & \\
\hline
\end{tabular}

${ }^{\mathrm{a}-\mathrm{c}}$ Mean values within columns with a different letter are significantly different $(P=0.05)$.

tivariate statistical analysis, whether a combination of these variables would give better results in distinguishing between the groups. Principal component analysis was performed on a data set (data set B) of 3 variables

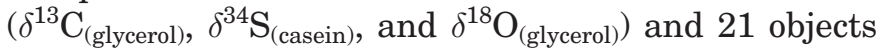
(7 local dairy, 4 factory, and 10 imported samples). The results of the PCA showed that the presence of a sulfur isotope ratio (the variable mainly correlated with the first component, responsible for $74.8 \%$ of total variance) distinguished the local dairy samples from the other 2

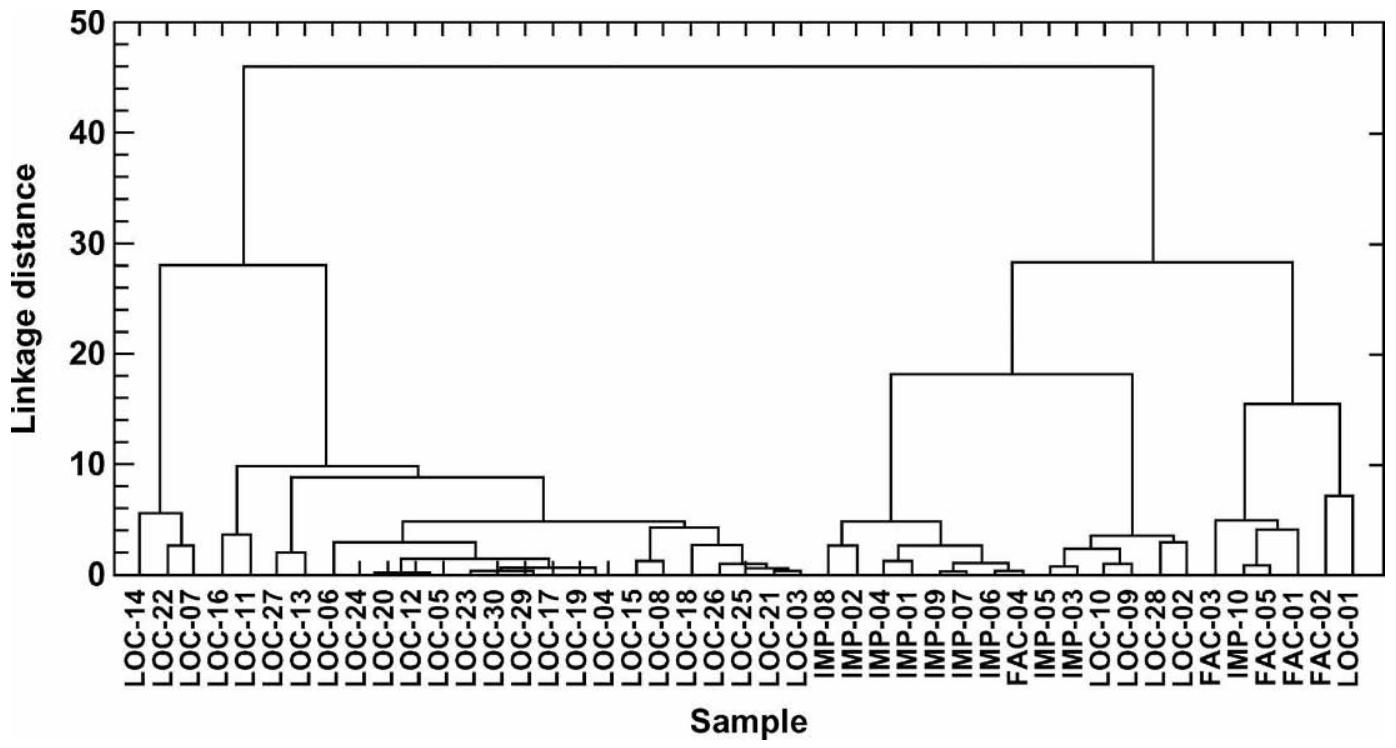

Figure 2. Dendrogram obtained by hierarchical cluster analysis of data set A (3 variables and 45 objects); LOC = local dairy product; FAC = factory product; and IMP = imported product. Most of the local dairy products were contained in one group, whereas imported and factory products together formed another group. 
TYPES OF CHEESE

* Imported product

- Factory product

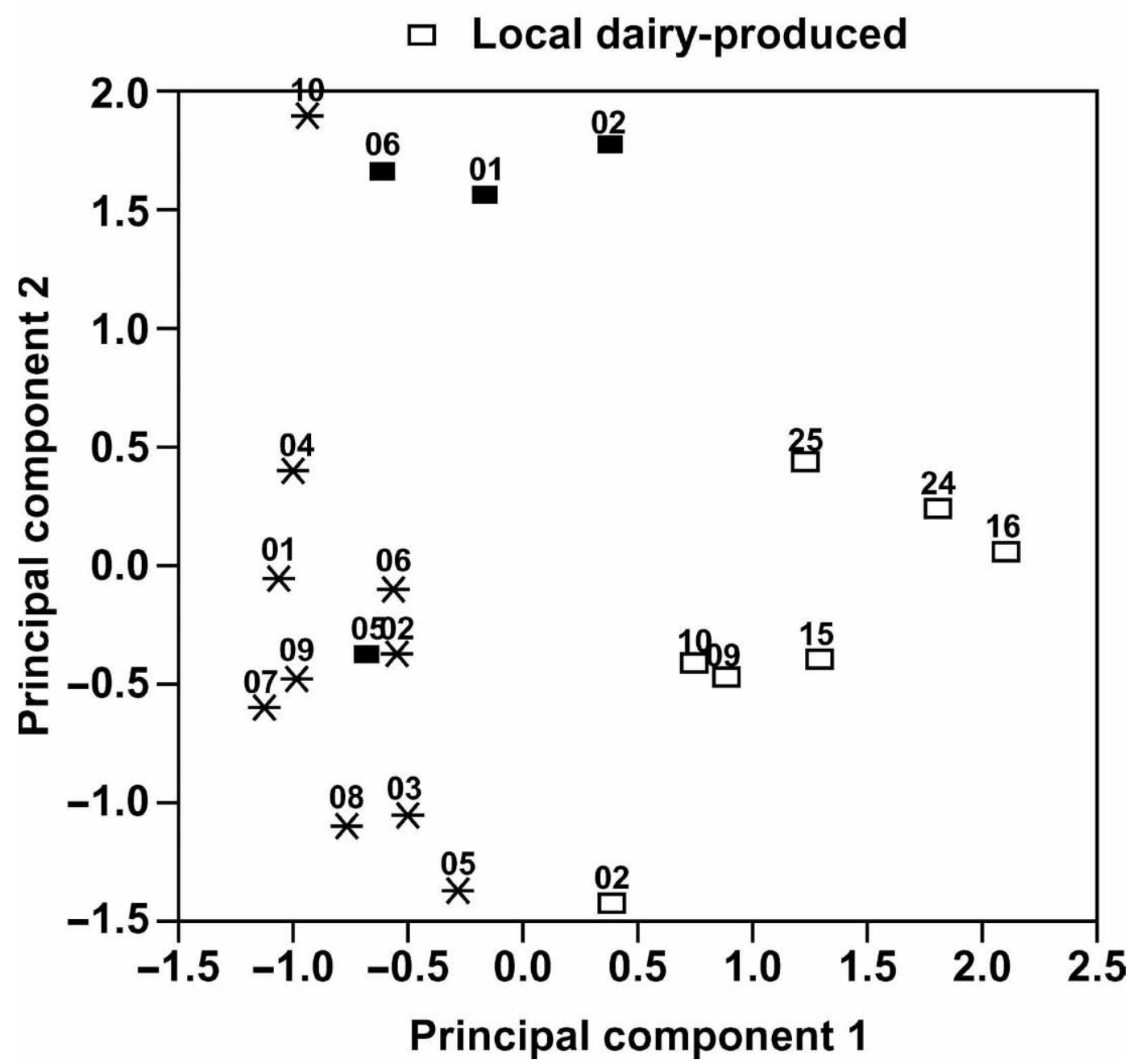

Figure 3. Scatter plot of the scores on the first 2 principal components obtained with data set B (3 variables and 21 objects). Local dairy products are distinct from the other 2 categories.

categories. In this case also, the factory samples were in the same group as the imported products (Figure 3 ), and HCA confirmed the presence of these 2 groups (Figure 4).

\section{CONCLUSIONS}

Multielement isotope ratio analysis was used to distinguish between 3 categories of cheeses (local dairy, factory, and imported products) that appear to be the same and are marketed under the "Peretta" name or an alternative brand. The results showed that the carbon isotope ratio measured in the casein fraction is strongly correlated with that determined in the glycerol fraction and therefore provides the same information. In both cases, Tukey's test revealed significant differences between the mean values of the 3 categories of cheese, attributable to the different diet of the cows.

The difference between the mean values was not significant for the nitrogen isotope ratio. The variability of this parameter within the production of local dairies could be ascribed to the diverse fertilization of the soil rather than to geoclimatic factors. A comparison of these data with those reported in the literature high- 


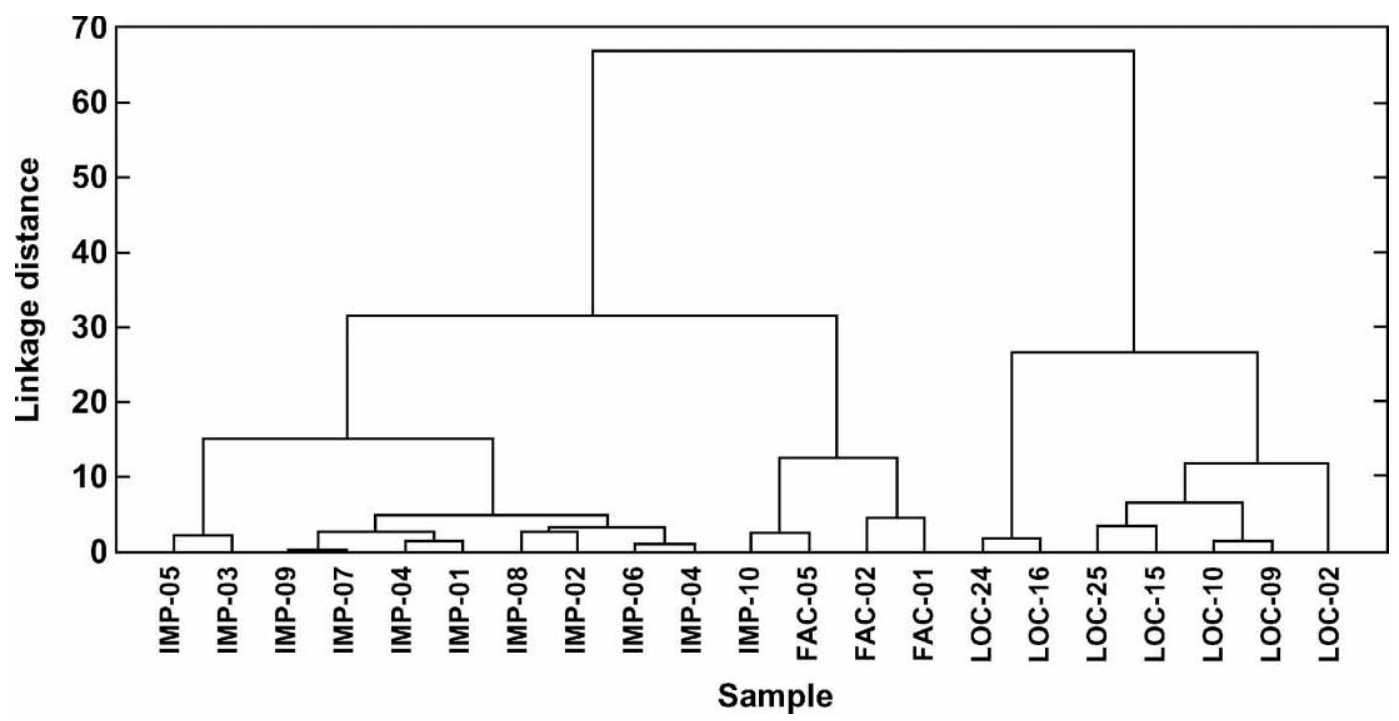

Figure 4. Dendrogram obtained by hierarchical cluster analysis of data set B (3 variables and 21 objects); LOC = local dairy product; FAC = factory product; and IMP = imported product. Local dairy products are contained in one group, whereas imported and factory products are together in another group.

lights the variability of this parameter in relation to year of production.

Mean values of the oxygen isotope ratio were also significantly different in the 3 categories of products. Significant differences were found between the local dairy products and cows' milk cheeses made in Northern Europe. Within the group of local dairy samples of definite Sardinian origin, no significant differences were found in the carbon, nitrogen, and oxygen isotope ratios linked to area of production. Tukey's test showed differences also between the mean values of the sulfur isotope ratio in samples of the 3 types of cheese whereas differences in the mean values of $\delta^{2} \mathrm{H}$ were observed between the imported samples and cheese in the other 2 categories. Multivariate statistical analysis (PCA and HCA) revealed that the factory samples, made from milk produced by intensive farming, had isotope characteristics that were very similar to those of the imported samples, and formed a single group together with some local dairy samples. The remaining products of local dairies formed a second group.

Multivariate statistical analysis combined the isotope ratios that best distinguished the 3 categories of cheeses $\left(\delta^{13} \mathrm{C}_{(\text {glycerol })}, \delta^{34} \mathrm{~S}_{(\text {casein) }}\right.$, and $\left.\delta^{18} \mathrm{O}_{\text {(glycerol) }}\right)$. This allowed the samples from local dairies to be distinguished from the other 2 types of products and confirmed the similarity between the factory and imported cheeses.

Our results show that the isotope ratios analyzed can make an important contribution to safeguarding "Peretta" type cheese, a typical Sardinian cheese made by traditional methods from raw materials produced in the place of origin.

\section{ACKNOWLEDGMENT}

This work was financially supported by the project COFIN-MURST 2000.

\section{REFERENCES}

Amberger, A., and H. L. Schmidt. 1987. Natürliche Isotopengehalte von Nitrat als Indikatoren für dessen Herkunft. Geochim. Cosmochim. Acta 51:2699-2705.

Beresford, T. P., N. O. Fitzsimons, N. L. Brennan, and T. M. Cogan. 2001. Recent advances in cheese microbiology. Int. Dairy J. 11:259-274.

Brescia, M. A., V. Caldarola, G. Buccolieri, A. Dell'Atti, and A. Sacco. 2003. Chemometric determination of the geographical origin of cow milk using ICP-OES data and isotopic ratios: A preliminary study. Ital J. Food Sci. 15:329-336.

Brescia, M. A., M. Monfreda, A. Buccolieri, and C. Carrino. 2004. Characterisation of the geographical origin of buffalo milk and Mozzarella cheese by means of analytical and spectroscopic determinations. Food Chem. 89:139-147.

Bugaud, C., S. Buchin, J. B. Coulon, and A. Hauwuy. 2001. Relationships between flavour and chemical composition of Abundance cheese derived from different types of pastures. Lait 81:593-607.

Camin, F., G. C. Coloru, D. Depentori, M. A. Franco, G. Manca, and G. Versini. 2001. Dieta-origine geografica, latte e formaggio: Riscontri con l'analisi isotopica. Pages $132-145$ in Proc. II Int. Mtg. Associazione Nazionale Formaggi Sotto il Cielo-Agenzia Lucana per lo Sviluppo (ANFOSC-ALSIA), Bella, Italy. L'AquiloneLa Bottega della Stampa, Potenza, Italy.

Camin, F., K. Wietzerbin, A. Blanch Cortes, G. Haberhauer, M. Lees, and G. Versini. 2004. Application of multielement stable isotope ratio analysis to the characterisation of French, Italian, and Spanish cheeses. J. Agric. Food Chem. 21:6592-6601.

Chiacchierini, E., P. Bogoni, M. A. Franco, M. Giaccio, and G. Versini. 2002. Characterisation of the regional origin of sheep and cow 
cheeses by casein isotope ${ }^{13} \mathrm{C} /{ }^{12} \mathrm{C}$ and ${ }^{15} \mathrm{~N} /{ }^{14} \mathrm{~N}$ ratios. J. Commodity Sci. 41:303-315.

Clark, I., and P. Fritz. 1997. Environmental Isotopes in Hydrogeology. Lewis Publishers, New York, NY.

De Niro, M. L., and S. Epstein. 1978. Influence of the diet on the distribution of carbon isotopes in animals. Geochim. Cosmochim. Acta 42:495-506.

Giaccio, M., A. Del Signore, F. Di Giacomo, P. Bogoni, and G. Versini. 2003. Characterisation of cow and sheep cheeses in a regional scale by stable isotope ratios of casein $\left({ }^{13} \mathrm{C} /{ }^{12} \mathrm{C}\right.$ and $\left.{ }^{15} \mathrm{~N} /{ }^{14} \mathrm{~N}\right)$ and glycerol ${ }^{18} \mathrm{O} /{ }^{16} \mathrm{O}$. J. Commodity Sci. 42:193-204.

Heaton, H. T. E. 1987. The ${ }^{15} \mathrm{~N} /{ }^{14} \mathrm{~N}$ ratios of plants in South Africa and Namibia: Relationship to climate and coastal/saline environments. Oecologia 74:236-246.

Kornexl, B. E., T. Werner, A. Rossmann, and H. L. Schmidt. 1997. Measurement of stable isotope abundances in milk and milk ingredients-A possible tool for origin assignment and quality control. Z. Lebensm. Unters. Forsch. 205:19-24.

Kreitler, C. W., and D. C. Jones. 1975. Natural soil nitrate: The cause of the nitrate contamination of groundwater in Runnels County, Texas. Ground Water 13:53-62.

Manca, G., F. Camin, G. Coloru, A. Del Caro, D. Detentori, M. A. Franco, and G. Versini. 2001. Characterization of the geographical origin of Pecorino Sardo cheese by casein stable isotope $\left({ }^{13} \mathrm{C} /\right.$ ${ }^{12} \mathrm{C}$ and $\left.{ }^{15} \mathrm{~N} /{ }^{14} \mathrm{~N}\right)$ ratios and free amino acid ratios. J. Agric. Food Chem. 49:1404-1409.

Mariotti, A., J. C. Germon, P. Hubert, P. Kaiser, R. Letolle, A. Tardiux, and P. Tardiux. 1981. Experimental determination of nitrogen kinetic isotope fractionation: Some principles; illustration for the denitrification and nitrification processes. Plant Soil 62:413-430.

Pillonel, L., R. Badertscher, P. Froidevaux, G. Haberhauer, S. Hölzl, P. Horn, A. Jakob, E. Pfammatter, U. Piantini, A. Rossmann, R. Tabacchi, and J. O. Bosset. 2003. Stable isotope ratios, major, trace and radioactive elements in Emmental cheeses of different origins. Lebensm. Wiss. Technol. 36:615-623.
Renou, J. P., C. Deponge, P. Gachon, J. C. Bonnefoy, J. B. Coulon, J. P. Garel, R. Veritè, and P. Ritz. 2004. Characterization of animal products according to geographic origin and feeding diet using nuclear magnetic resonance and isotope ratio mass spectrometry: Cow milk. Food Chem. 85:63-66.

Rossmann, A. 2001. Determination of stable isotope ratios in food analysis. Food Rev. Int. 17:347-381.

Rossmann, A., B. E. Kornexl, G. Versini, F. Pichlmayer, and G. Lamprecht. 1998. Origin assignment of milk from alpine regions by multielement stable isotope ratio analysis (SIRA). J. Food Sci. Nutr. 1:9-21.

Schmidt, H. L., R. Werner, and A. Rossmann. 2001. ${ }^{18} \mathrm{O}$ pattern and biosynthesis of natural plant products. Phytochemistry 58:9-32.

Sieper, H. P., and H. J. Kupka. 2003. New instrumentation concepts for simultaneous CNS- and O-IRMS analysis in natural micro and macro samples. Pages 90-91 in Proc. 2nd Int. Symp. on Isotopomers, Stresa, Italy.

Stefanon, B., and G. Procida. 2004. Effects of including silage in the diet on volatile compound profiles in Montasio cheese and their modification during ripening. J. Dairy Res. 71:58-65.

Wassenaar, L. I., and K. A. Hobson. 2003. Comparative equilibration and online technique for determination of non-exchangeable hydrogen of keratins for use in animal migration studies. Isotopes Environ. Health Stud. 39:211-217.

Weber, D., H. Kexel, and H. L. Schmidt. 1997. 13C-Pattern of natural glycerol: Origin and practical importance. J. Agric. Food Chem. 45:2042-2046.

Yoneyama, T. 1995. Nitrogen metabolism and fractionation of nitrogen isotopes in plants. Pages 92-102 in Stable isotopes in the biosphere. E. Wada, T. Yoneyama, M. Minagawa, T. Ando and B. D. Fry, ed. Kyoto University Press, Kyoto, Japan.

Zainal, M., C. Vallet, and G. J. Martin. 1999. Stable isotope characterization of milk components and whey ethanol. J. Agric. Food Chem. 47:4693-4699. 